\title{
Bonzo/CXCR6 expression defines type 1-polarized T-cell subsets with extralymphoid tissue homing potential
}

\author{
Chang H. Kim, ${ }^{1}$ Eric J. Kunkel, ${ }^{1}$ Judie Boisvert, ${ }^{2}$ Brent Johnston, ${ }^{1}$ James J. Campbell, ${ }^{1}$ \\ Mark C. Genovese, ${ }^{3}$ Harry B. Greenberg, ${ }^{2}$ and Eugene C. Butcher ${ }^{1}$ \\ ${ }^{1}$ Laboratory of Immunology and Vascular Biology, Department of Pathology, and \\ ${ }^{2}$ Department of Microbiology and Immunology, Center for Molecular Biology and Medicine, \\ Veterans Affairs Palo Alto Health Care System, Palo Alto, California, USA \\ ${ }^{3}$ Division of Immunology and Rheumatology, Stanford University School of Medicine, Stanford, California, USA \\ Address correspondence to: Chang H. Kim, 3801 Miranda Avenue, Mail Code 154-B, \\ VAMC Building 101, Room C4-111, Palo Alto, California 94304, USA. \\ Phone: (650) 493-5000 ext.63167; Fax: (650) 858-3986; E-mail: chkim@stanford.edu.
}

Received for publication December 1, 2000, and accepted in revised form January 29, 2001.

Chemokine receptor expression is finely controlled during T-cell development. We show that newly identified chemokine receptor Bonzo/CXCR6 is expressed by subsets of Th1 or T-cytotoxic 1 (Tc1) cells, but not by Th2 or Tc2 cells, establishing Bonzo as a differential marker of polarized type 1 $T$ cells in vitro and in vivo. Priming of naive T cells by dendritic cells induces expression of Bonzo on T cells. IL-12 enhances this dendritic cell-dependent upregulation, while IL-4 inhibits it. In blood, $35-56 \%$ of Bonzo ${ }^{+} \mathrm{CD} 4 \mathrm{~T}$ cells are Th1 cells, and $60-65 \%$ of Bonzo ${ }^{+} \mathrm{CD} 8 \mathrm{~T}$ cells are $\mathrm{Tc} 1$ cells, while few Bonzo $^{+}$cells are type $2 \mathrm{~T}$ cells. Almost all Bonzo ${ }^{+} \mathrm{Tc} 1$ cells contain preformed granzyme A and display cytotoxic effector phenotype. Most Bonzo ${ }^{+}$T cells lack L-selectin and/or CCR7, homing receptors for lymphoid tissues. Instead, Bonzo ${ }^{+} \mathrm{T}$ cells are dramatically enriched among $\mathrm{T}$ cells in tissue sites of inflammation, such as rheumatoid joints and inflamed livers. Bonzo may be important in trafficking of effector $\mathrm{T}$ cells that mediate type 1 inflammation, making it a potential target for therapeutic modulation of inflammatory diseases.

J. Clin. Invest. 107:595-601 (2001).

\section{Introduction}

Migration of specific lymphocyte populations is controlled at multiple levels by chemokines and adhesion molecules (1). Over 50 chemokines and 19 chemokine receptors have been identified thus far (2). The large number of chemokines and receptors and their ability to act sequentially to mediate multistep lymphocyte navigation confers specificity to the process of lymphocyte trafficking and microenvironmental localization (3), while the existence of promiscuity in chemokine-receptor pairings and overlap in cell and tissue expression is thought to provide significant redundancy at each step, enhancing the robustness of migratory processes (4).

$\mathrm{T}$-cell progenitors in the thymus undergo maturation processes generating naive $T$ cells, and these naive thymic T-cell emigrants differentiate to functionally mature memory and effector $\mathrm{T}$ cells in lymphoid and peripheral tissues. B cells undergo similar differentiation processes in bone marrow and lymphoid tissues. Importantly, these differentiation processes for $\mathrm{T}$ and $\mathrm{B}$ cells also bring changes in chemokine receptor expression pattern along with other effector functions, thereby changing their migratory behavior to match their function (5-7). Although it remains to be confirmed in vivo, some chemokine receptors are preferentially expressed by $\mathrm{T}$ cells generated in vitro under Th1 (CXCR3 and CCR5) or in Th2 (CCR3, CCR4, and CCR8) polarization conditions (8-12). Bonzo (also called STRL33, TYMSTR, or CXCR6) is a receptor for CXCL16, and was described previously as a fusion cofactor for HIV-1 and SIV (13, 14). In humans, Bonzo is expressed by small subsets of T cells and CD $16^{+}$cells, but not by B cells, monocytes, or dendritic cells (15). In mice, a subset of CD4, CD8, and natural killer T cells (NKT cells) have the receptor for the Bonzo ligand, CXCL16 (13).

We report here that Bonzo defines unique subsets of highly polarized type 1 memory/effector T cells in vivo, and Bonzo expression is tightly regulated by dendritic cells and Th $1 / 2$ cytokines. These Bonzo type $1 \mathrm{~T}$ cells display tissue-homing potential and are enriched in inflamed tissues, suggesting its novel role in mediation of type I inflammation.

\section{Methods}

$A b$ 's. Ab's to CLA (HECA 452) and CD62L (DREG-200) were generated in our lab (E.C. Butcher). Anti-CD56 (NKL-nbl-1) and anti-CD69 $(\mathrm{CH} / 4)$ were from Caltag Laboratories Inc. (Burlingame, California, USA), and anti-IL-4 (3010.211) was purchased from Becton Dickinson Immunocytometry Systems (Mountain View, California, USA). The mAb to Bonzo (clone 56811.111) was purchased from R\&D Systems Inc. (Minneapolis, Minnesota, USA). Ab's to $\alpha 4 \beta 7$ (ACT-1) and CCR7 (7H12-12-2) were obtained from LeukoSite Inc. (Cambridge, Massachusetts, USA). Anti-TCR-Vo24 (C15) 


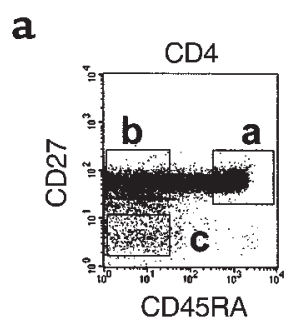

C

Frequency of Th1, Th2, or Th0 in each subset (bars = averages)

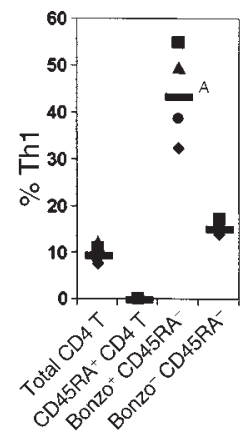

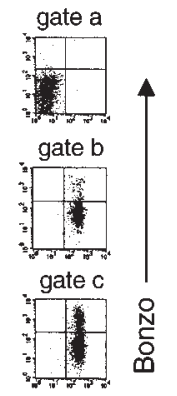

CD45RO

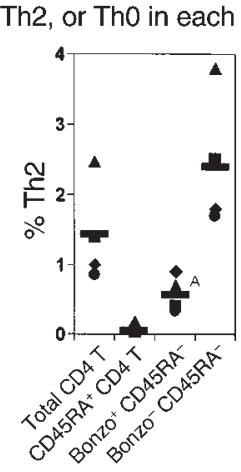

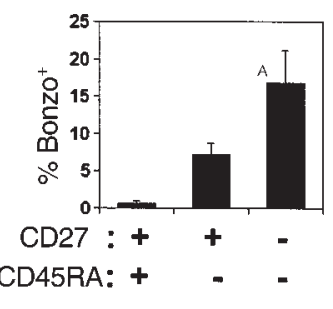

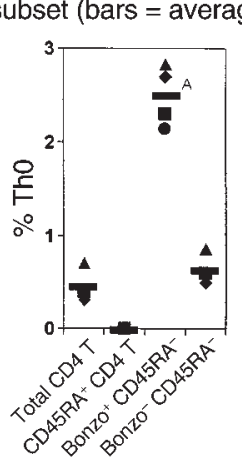

b Total
CD4 T

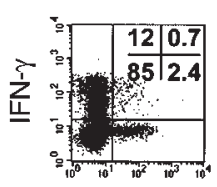

Naive (CD45RA ${ }^{+}$ Bonzo+
CD45RA Bonzo-
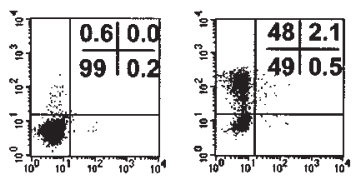

IL-4

d

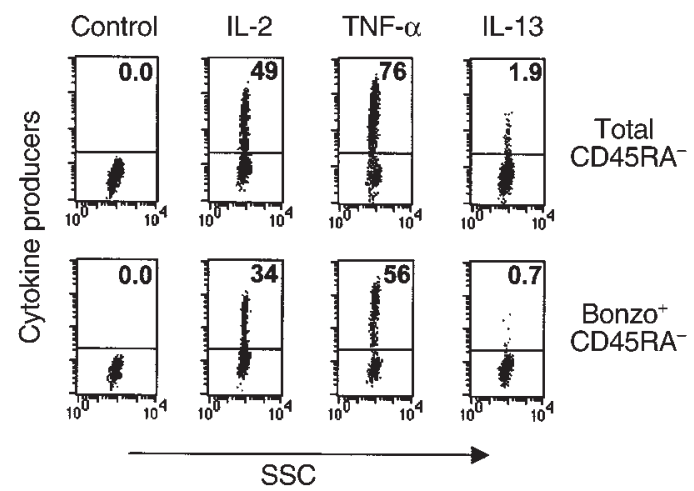

\section{Figure 1}

Bonzo is expressed by blood CD4 ${ }^{+}$Th1 memory/effector T cells. (a) Expression of Bonzo by CD27 $17^{+-}$memory CD4. (b-d) Cytokine production by $\mathrm{Bonzo}^{+-} \mathrm{CD} 4 \mathrm{~T}$ cells. Th1 cells are producers of IFN- $\gamma$ but not IL-4; Th2 cells are producers of IL-4 but not IFN- $\gamma$; Th0 cells are producers of both IFN- $\gamma$ and IL-4. CD4 T cells prestained with anti-Bonzo and anti-CD45RA were activated by PMA and ionomycin for 4 hours before further staining of intracellular cytokines. Data are representative of at least four experiments using $T$ cells from different donors. Symbols in c represent different donors. Bars indicate averages of four independent experiments (c). ASignificant difference $P<0.03$ between $\mathrm{CD} 27^{+}$and $\mathrm{CD} 27^{-} \mathrm{T}^{-}$cells in a or Bonzo+ ${ }^{+}$and Bonzo- memory $\mathrm{T}$ cells in $\mathbf{c}$.

and anti-TCR-Vß11 (C21) were from Immunotech (Marseilles, France). Ab's to the following antigens were obtained from PharMingen (San Diego, California, USA): CD4 (RPA-T4), CD19 (HIB19), CD27 (M-T271), CD45RA (HI100), CD45RO (UCHL1), CD161 (DX12), IL-2 (MQ1-17H12), IL-10 (JES3-19F1), IL-13 (JES10$5 A 2)$, IFN- $\gamma$ (4S.B3), granzyme A (CB9), and TNF- $\alpha$ (mAb11). Anti-CD3 (UCHT1) is from Sigma Chemical Co. (St. Louis, Missouri, USA).

Cell preparation and culture. Human PBMCs (Stanford University Blood Center, Stanford, California, USA) were prepared by density gradient centrifuge on Histopaque-1077 (Sigma Chemical Co.). Untouched $\mathrm{CD}^{+}$or $\mathrm{CD}^{+} \mathrm{T}$ cells (purity $>97 \%$ ) were isolated by depleting non-T cells using a magnetic bead-depletion method (Miltenyi Biotec, Auburn, California, USA). All human subject protocols were approved by the Institutional Review Board at Stanford University. Synovial fluid was obtained from rheumatoid or psoriatic arthritis patients undergoing diagnostic arthrocentesis. Inflamed liver was obtained from patients (hepatitis $\mathrm{C}$ virus $\left[\mathrm{HCV}^{+}\right]$and alcoholic cirrhosis) undergoing liver transplantation at Stanford University Medical Center. Lymphocytes were isolated from explant livers by first cutting the liver into small $1-\mathrm{cm}^{2}$ pieces, washing in RPMI-1640 supplemented with 10\% FBS, then homogenizing into a cell suspension with a Stomacher 400
(Seward, London, United Kingdom). The resulting liver cell suspension and diluted synovial fluid (1:2 in PBS) were centrifuged at $250 \mathrm{~g}$ before being layered over Ficoll (Amersham Pharmacia Biotech, Piscataway, New Jersey, USA) to isolate the mononuclear layer.

Peripheral blood CD $14^{+}$monocytes (purity > 95\%) were isolated by magnetic sorting (Miltenyi Biotec). Immature dendritic cells were generated from the $\mathrm{CD} 14^{+}$monocytes by culturing them for 5 days in RPMI-1640 medium (10\% FBS) supplemented with IL-4 (1,000 U/ml; PharMingen) and GM-CSF (50 $\mathrm{ng} / \mathrm{ml}$; R\&D Systems Inc.). Immature dendritic cells (DCs) were maturated by LPS $(0.5 \mu \mathrm{g} / \mathrm{ml}$; Sigma Chemical Co.) for 24 hours. Naive CD45RO- CD4 $T$ cells were cultured with DCs (ratio of 10:1) for 5 days in the presence or absence of IL-4 $(1,000 \mathrm{U} / \mathrm{ml})$ or IL-12 (20 ng/ml; R\&D Systems Inc.).

FACS analysis. Bonzo expression was detected using unconjugated anti-Bonzo mAb (or isotype-matched control mAb's), a biotinylated horse anti-mouse IgG secondary Ab (Vector Laboratories, Burlingame, California, USA), and streptavidin peridinin chlorophyll protein (streptavidin-PerCP) or streptavidin-APC (PharMingen). Lymphocytes were stained with antiBonzo and other $\mathrm{mAb}$ 's to examine Bonzo expression on $\mathrm{CD} 4 \mathrm{~T}$ cells $\left(\mathrm{CD}^{+} \mathrm{CD} 45 \mathrm{RA}^{+/-} \mathrm{CD} 27^{+/-}\right), \mathrm{CD} 8$ $\mathrm{T}$ cells $\left(\mathrm{CD}^{+} \mathrm{CD}^{2} 5 \mathrm{RA}^{+/-} \mathrm{CD} 27^{+/-} \mathrm{CD} 56^{+/-}\right)$, B cells 
$\left(\mathrm{CD} 19^{+} \mathrm{IgD}^{+/-}\right)$, granulocytes $\left(\mathrm{CD} 15^{+}\right)$, monocytes $\left(\mathrm{CD} 14^{+}\right)$, NK cells $\left(\mathrm{CD} 3^{-} \mathrm{CD} 56^{+}\right)$, and NKT cells (TCR$\left.\mathrm{V} \alpha 24^{+} \mathrm{V} \beta 11^{+} \mathrm{CD} 161^{\text {bright }}\right)$. Tissue lymphocytes were stained and gated for CD3 (or TCR- $\alpha \beta$ ) expression, then further subdivided by CD4 or CD8 expression and CD69 expression. Four-color flow cytometry was done on a FACScalibur (Becton Dickinson Immunocytometry Systems) using CellQuest software, version 3.1 (Becton Dickinson Immunocytometry Systems). Analyses of intracellular cytokines and effector molecules. Cells prestained with anti-Bonzo and anti-CD45RA were activated for 4 hours at $37^{\circ} \mathrm{C}$ with PMA $(50 \mathrm{ng} / \mathrm{ml})$ and ionomycin $(1 \mu \mathrm{g} / \mathrm{ml})$ in RPMI-1640 medium supplemented with penicillin/streptomycin, $10 \% \mathrm{FBS}$, and 10 $\mu \mathrm{g} / \mathrm{ml}$ monensin (Sigma Chemical Co.). Activated cells were fixed and permeabilized using Cytofix/Cytoperm solution (PharMingen) and stained with phycoerythrinconjugated isotype control Ab's or mAb's to IL-2, IL-4, IL-13, IFN- $\gamma$, and TNF- $\alpha$. Intracellular granzyme A was detected by the same method used for cytokine analysis, except that cells were not activated. Data were analyzed on a FACScalibur using CellQuest software (Becton Dickinson Immunocytometry Systems).

Statistical analyses. Student's $t$ test was used. $P$ values less than 0.05 were considered to be significant differences.

\section{Results}

Bonzo is expressed by polarized type $1 \mathrm{~T}$ cells. Lymphocyte expression of chemokine receptors is developmentally regulated, and determining the precise temporal and spatial points of chemokine-receptor expression is instrumental in understanding selective trafficking of lymphocyte subsets. We closely examined Bonzo expression by heterogeneous CD4 memory T-cell subsets: $\mathrm{CD} 27^{+} \mathrm{CD} 45 \mathrm{RA}^{-} \mathrm{CD} 45 \mathrm{RO}^{+}$ and $\mathrm{CD}^{2} 7^{-} \mathrm{CD} 45 \mathrm{RA}^{-} \mathrm{CD} 45 \mathrm{RO}^{+}$cells, the latter of which is known to be functionally more differentiated in terms of effector cytokine production and expression of adhesion molecules (16). Although Bonzo is expressed by both populations, it is expressed by a greater proportion of the more functionally mature CD27- cells (Figure 1a).

Th1 and Th 2 cells are enriched in CD27- CD4 T cells. Thus, we examined whether Bonzo is expressed preferentially by Th1 or Th2 cells. Freshly isolated blood $\mathrm{T}$ cells were stimulated for 4 hours with PMA and ion-

\section{Figure 2}

Bonzo is expressed by blood CD8 ${ }^{+} \mathrm{Tc} 1$ memory/effector T cells. (a and $\mathbf{b}$ ) Production of IFN- $\gamma$ and IL-4 by Bonzo ${ }^{+/-}$T cells. Expression of intracellular granzyme $A(c)$ and surface effector cytotoxic cell marker CD56 (d) by Bonzo ${ }^{+-}$CD8 T cells. Tc1 cells are producers of IFN- $\gamma$ but not IL-4; Tc2 cells are producers of IL-4 but not IFN- $\gamma$; Tc0 cells are producers of both IFN- $\gamma$ and IL-4. Data are representative of at least four experiments with different donors. Symbols in $\mathbf{b}$ and $\mathbf{d}$ represent different donors. Bars represent averages of multiple donors. Thick and thin lines in $c$ represent staining with antigranzyme $A$ and isotype control Ab's respectively. ${ }^{A}$ Significant differences $P<0.04$ between Bonzo ${ }^{+}$and Bonzo- CD45RA- CD8 T cells. omycin and examined for their intracellular cytokine production capacity (Figure $1 \mathrm{~b}$ ). Bonzo ${ }^{+} \mathrm{CD} 4 \mathrm{~T}$ cells contain many more Th 1 (IFN- $\gamma$ producers) and Th0 (IFN- $\gamma$ and IL-4 producers) than Bonzo memory CD4 T cells (Figure 1, b and c). Very few Th2 cells are found in the Bonzo ${ }^{+} \mathrm{CD} 4 \mathrm{~T}$-cell population. In this regard, IL-13 producers were also poorly represented among Bonzo $^{+}$CD4 memory T cells (Figure $1 \mathrm{~d}$ ). Bonzo ${ }^{+}$CD 4 $T$ cells contain moderate numbers of TNF- $\alpha$ or IL- 2 producers, a lower percentage than in Bonzo- CD4 memory $T$ cells (Figure 1d).

CD8 T cells also contain T-cytotoxic 1 (Tc1) and Tc2 subsets. Since Bonzo is specifically expressed by Th1 cells versus Th2 cells, we examined whether Bonzo is also preferentially expressed by Tc1. Similar to Bonzo ${ }^{+}$CD 4

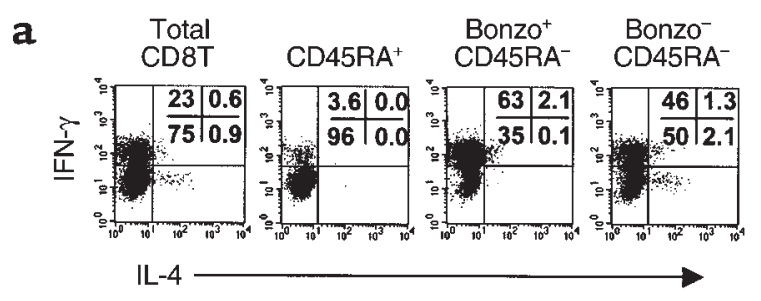

b Frequency of $T c 1, T c 2$, or $T c 0$ in each subset (bars = averages)
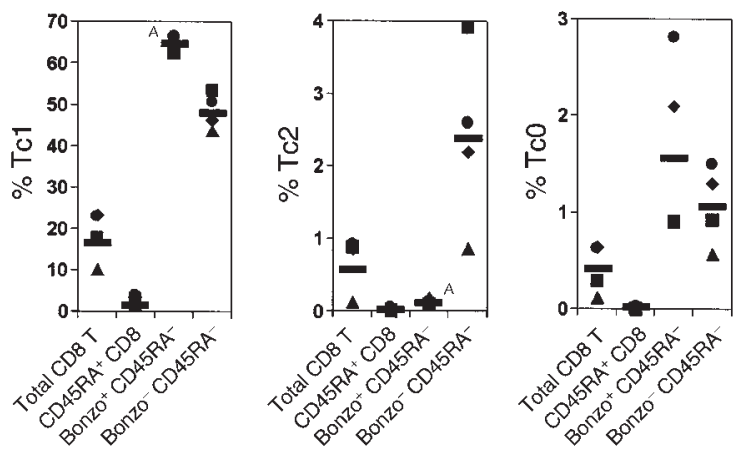

c
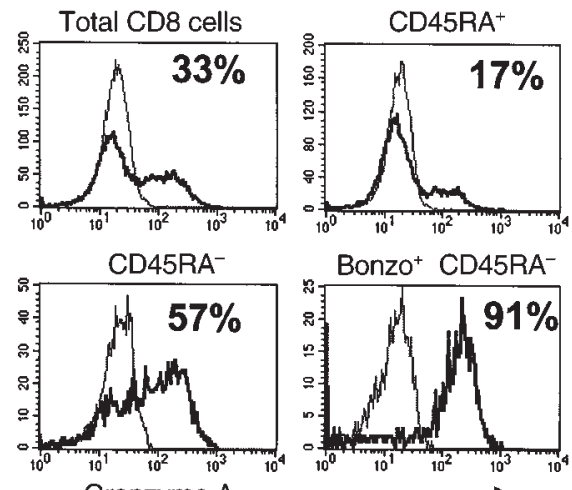

Bonzo $^{+}$CD45RA $^{-}$

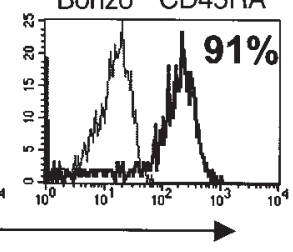

d

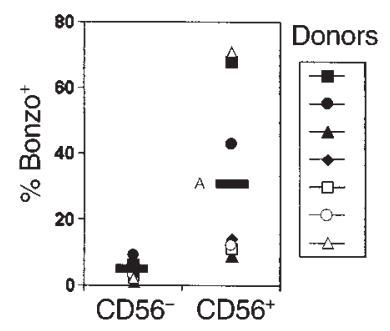


a
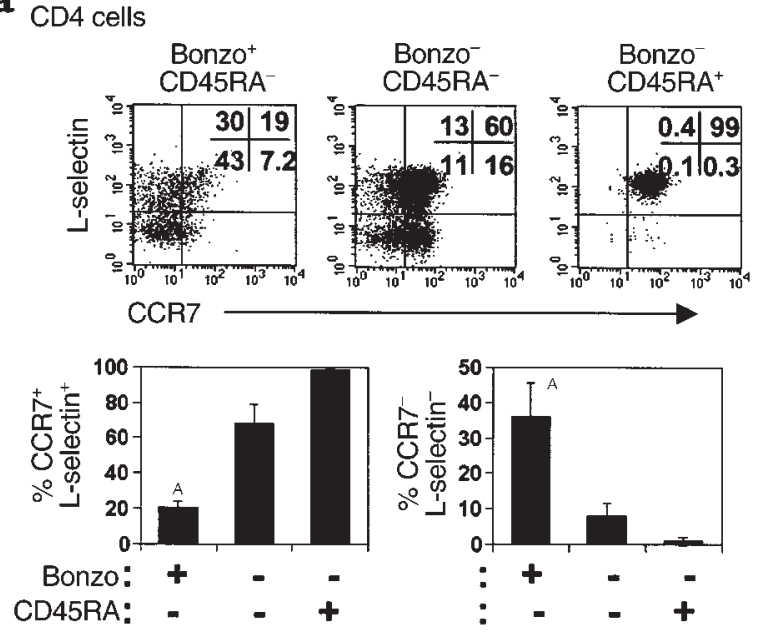

b
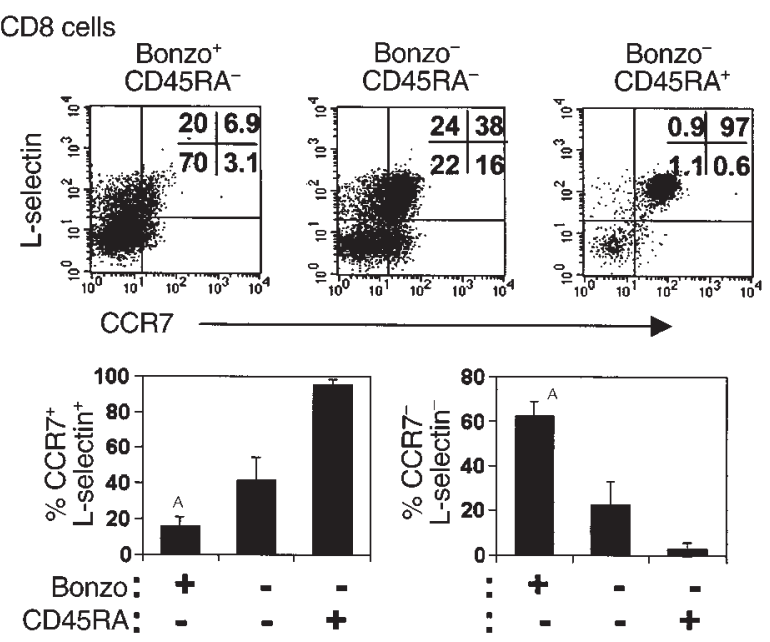

Figure 3

Homing receptor expression by Bonzo ${ }^{+}$and Bonzo- CD4 or CD8 T-cell subsets. Expression of CCR7 and L-selectin/CD62L was examined on peripheral blood Bonzo ${ }^{+}$and Bonzo ${ }^{-} \mathrm{CD} 4(\mathbf{a})$ or $\mathrm{CD} 8(\mathbf{b})$ populations. Data are representative of at least three experiments with different

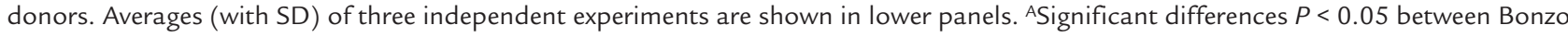
positive and negative populations.

T cells, Bonzo ${ }^{+} \mathrm{CD} 8$ cells contain more Tc1 (IFN- $\gamma$ producers) than Bonzo- CD45RA- CD8 T cells, but almost no Tc2 (IL-4 producers) (Figure 2, a and b).

Granzymes are important effector molecules of cytotoxic lymphocytes and induce granule-mediated apoptosis of target cells (17). Intracellular granzyme A content was examined in Bonzo positive and negative CD8 $\mathrm{T}$ cells (Figure 2c). The vast majority of Bonzo $^{+}$CD8 T cells (80-90\%) were positive for intracellular granzyme A, compared with total CD45RA or CD45RA- CD8 T cells. Thirteen to fifty-six percent of granzyme $\mathrm{A}^{+}$cells were $\mathrm{Bonzo}^{+}$(average $=34, n=5$ ), while $0.7-6 \%$ of granzyme $\mathrm{A}^{-}$cells were $\mathrm{Bonzo}^{+}$(average $=3.6, n=5)$. $\mathrm{CD} 56^{+} \mathrm{CD} 8 \mathrm{~T}$ cells are effector cells with strong cytotoxic activity against target cells (18). In this regard, greater percentages of $\mathrm{CD} 56^{+}$effector $\mathrm{CD} 8 \mathrm{~T}$ cells are $\mathrm{Bonzo}^{+}$than less cytotoxic CD56CD8 cells (Figure 2d). We conclude that Bonzo is selectively expressed by highly differentiated effector IFN- $\gamma$-producing Th 1 cells and by $\mathrm{CD}^{2} 6^{+}$granzyme $\mathrm{A}^{+}$Tc1 effector CD8 cells.

Bonzo ${ }^{+} T$ cells have extralymphoid tissue-homing potential. To assess the homing potential of Bonzo ${ }^{+} \mathrm{T}$ cells, expression of important homing receptors was examined on $\mathrm{Bonzo}^{+}$and Bonzo- $\mathrm{T}$ cells. CCR7 is the chemokine receptor for SLC and ELC, two chemokines implicated in lymphocyte homing into and migration within lymphoid tissues (19). CCR7 is expressed by many lymphocytes that also express L-selectin (CD62L) (20), a homing receptor for addressins found on lymph node high endothelial venules. Fewer than $20 \%$ of Bonzo $^{+} \mathrm{CD} 4 \mathrm{~T}$ cells coordinately express CCR7 and CD62L, while almost all naive CD4 $\mathrm{T}$ cells and approximately $70 \%$ of Bonzo ${ }^{-}$memory CD $4 \mathrm{~T}$ cells express them. On average, $40 \%$ of Bonzo ${ }^{+} \mathrm{CD} 4$ cells lack both
CCR7 and CD62L, compared with fewer than $10 \%$ double-negative cells in the Bonzo- populations (Figure $3 a)$. Bonzo ${ }^{+} \mathrm{CD} 8 \mathrm{~T}$ cells also contain fewer lymphoid tissue homing phenotype $\mathrm{CCR} 7^{+} \mathrm{CD} 62 \mathrm{~L}^{+}$cells and more CCR7-CD62L- cells than Bonzo- CD8 T-cell subsets (Figure $3 \mathrm{~b}$ ). We conclude that approximately $80 \%$ of Bonzo ${ }^{+}$cells lack one or another of these homing receptors necessary for their migration into lymphoid organs. In line with this relative deficiency in expression of lymphoid tissue-homing receptors, Bonzo ${ }^{+}$ $\mathrm{T}$ cells contain larger numbers of skin-homing $\mathrm{CLA}^{+}$ cells and gut-homing $\alpha 4 \beta 7^{+}$cells, when compared with

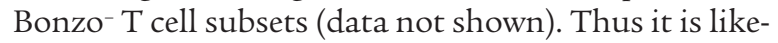
ly that circulating Bonzo ${ }^{+} \mathrm{T}$ cells preferentially migrate to extralymphoid tissue sites.

Enrichment of Bonz $0^{+} T$ cells in inflamed synovia and liver. The extralymphoid homing potential, type 1 cytokine production, and high effector function of Bonzo ${ }^{+} \mathrm{T}$ cells suggest a potential role in inflammatory tissues. We examined the presence of Bonzo $^{+} \mathrm{T}$ cells infiltrating arthritic synovial fluid and inflamed liver (Figure 4). All $\mathrm{CD} 4$ or CD8 T cells in inflamed synovial fluid were activated $\mathrm{CD} 69^{+}$lymphocytes. Bonzo ${ }^{+} \mathrm{CD} 4$ and $\mathrm{CD} 8 \mathrm{~T}$ cells were enriched in inflamed synovial fluid (Figure 4, a and b), compared with the blood counterparts. More T cells from rheumatoid arthritis synovial fluid $(\sim 60 \%)$ than from psoriatic arthritis synovial fluid ( $35 \%)$ expressed Bonzo. Bonzo ${ }^{+} \mathrm{CD} 4$ or CD8 $\mathrm{T}$ cells were also enriched in inflamed livers. Thirty-eight percent of CD4 $\mathrm{T}$ cells and $39 \%$ of CD8 T cells were CD69 ${ }^{+}(n=15) ; 49.4 \%$ of TCR$\alpha \beta{ }^{-} \mathrm{CD} 56^{+}$and $51 \%$ of TCR- $\alpha \beta^{+} \mathrm{CD} 56^{+}$cells were $\mathrm{CD} 69^{+}$ $(n=16)$. The majority of Bonzo+ liver CD4 or CD8 T cells are activated $\mathrm{T}$ cells expressing $\mathrm{CD} 69$, while the majority of resting $\mathrm{CD}^{-} 9^{-} \mathrm{T}$ cells were Bonzo ${ }^{-}$(Figure 4c). The majority of activated liver TCR- $\alpha \beta-\mathrm{CD} 56^{+} \mathrm{NK}$ cells and 


\section{Figure 4}

Bonzo is expressed on activated lymphocytes in tissue sites. FACS analysis of lymphocytes in the synovial fluid (SF) from patients with psoriatic arthritis (a) or rheumatoid arthritis (b) revealed that Bonzo is expressed on approximately $30 \%$ of both CD4 (range $24-35 \%$ ) and CD8 (range 20-31\%) lymphocytes in PsA and about $60-68 \%$ of CD 4 and about $61-70 \%$ of CD $8 T$ cells in RA, all of which expressed the activation marker CD69. In inflamed (alcoholic and $\mathrm{HCV}^{+}$) cirrhotic livers, Bonzo was expressed at high levels on $\mathrm{CD}^{2} 9^{+} \mathrm{CD} 4$ (range 3-11\% for CD69- and $24-56 \%$ for $\mathrm{CD}^{-} 9^{+}$) and CD8 (range 7-60\% for CD69- and 50-91\% for CD69+) lymphocytes (c). Bonzo expression was also high on TCR$\alpha \beta-C D 56^{+}$NK cells (50-92\%) and TCR- $\alpha \beta^{+} \mathrm{CD} 56^{+} \mathrm{T}$ cells (64-89\%) expressing CD69 (d). Representative Bonzo expression from an alcoholic cirrhotic liver is shown (c and d). Number of independent tissue samples of each type examined $(n)$ is shown.

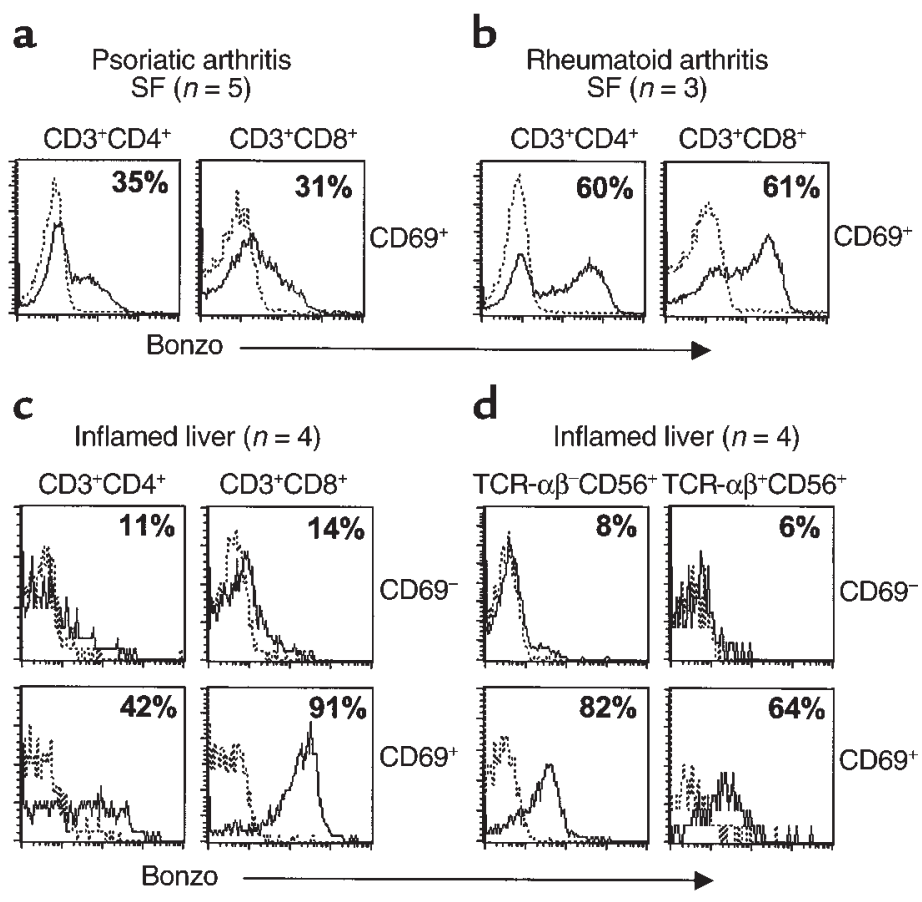

activated TCR- $\alpha \beta^{+} \mathrm{CD} 56^{+} \mathrm{T}$ cells also express Bonzo (Figure 4d). Similar patterns of Bonzo expression were observed in $\mathrm{HCV}^{-}$(inflamed by alcoholic cirrhosis) and $\mathrm{HCV}^{+}$livers (data not shown). Thus, Bonzo may be a general trafficking factor for memory/effector lymphocytes to highly inflamed tissue sites such as rheumatoid joints and chronically inflamed livers.

$D C$ differentiate naive $T$ cells to express Bonzo. Naive $\mathrm{T}$ cells that home to secondary lymphoid tissues are activated by specific antigen and DCs. Bonzo might be upregulated in lymphoid tissues on developing type 1 $\mathrm{T}$ cells during antigen priming by DCs. Alternatively, Bonzo could be induced on type 1 effector $T$ cells after homing into nonlymphoid inflammatory tissues. To ask if naive cells responding to antigen on DC could upregulate Bonzo, we generated allogenic monocytederived DCs to activate naive $\mathrm{T}$ cells and examined Bonzo expression by the resulting primed $\mathrm{T}$ cells. Naive $\mathrm{T}$ cells, which are small and Bonzo- become Bonzo $^{+}(\sim 5 \%)$ after 5 -day priming by mature DCs and 3 days of expansion, a frequency similar to in vivo-generated $\mathrm{Bonzo}^{+} \mathrm{CD} 4 \mathrm{~T}$ cells in blood (Figure 5). After the culture, most $\mathrm{T}$ cells display a memory $\mathrm{T}$-cell phenotype (CD45RA-CD45RO ${ }^{+}$, data not shown) and become bigger in size: evidence of priming and activation by DCs. We added IL-4 (a Th2 cytokine) or IL-12 (a Th1 cytokine) to the DC-T-cell cultures to see whether these Th1/2 cytokines would have any effect on DC-dependent Bonzo expression. IL-4 decreased induction of Bonzo on CD4 T cells (to $1-2 \%$ ), while IL-12 increased it (to $10-15 \%$ ). These results corroborate the fact that Bonzo is preferentially expressed by Th1 cells versus Th2 cells. Although we cannot rule out the possibility of further modulation of Bonzo expression in inflammatory tissues, these results clear- ly demonstrated that it can be induced on $\mathrm{T}$ cells during primary encounters with DCs.

\section{Discussion}

Bonzo defines bighly specialized memory/effector T cells in blood and tissues. Although controversial, in vitro and ex/in vivo studies have led to the proposal that expression of some chemokine receptors correlate with Th1 or Th2 polarization $(8,9,21-24)$. We demonstrate here that a specific chemokine receptor, Bonzo

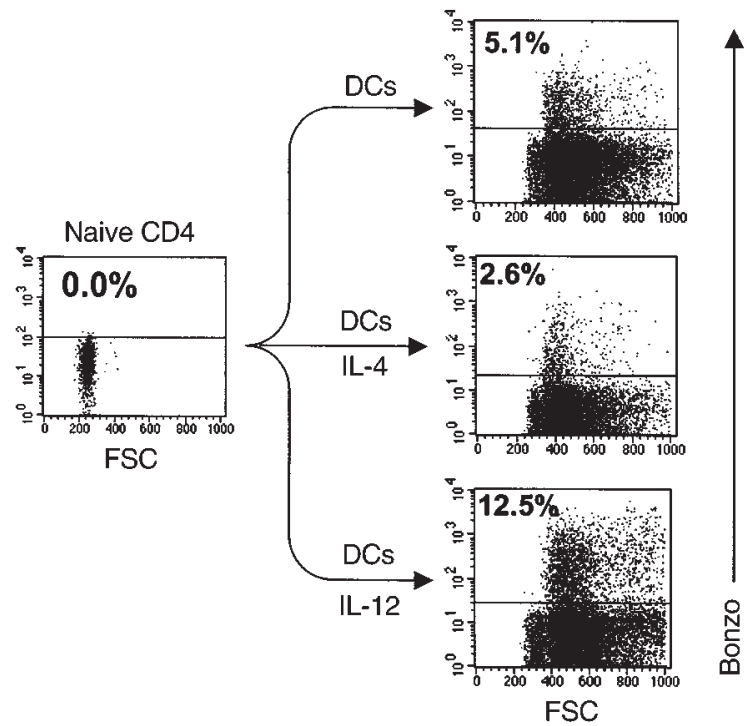

Figure 5

DCs induce naive T cells to express Bonzo. Naive (CD45RO-) CD4 T cells were cultured with mature monocyte-derived DCs (at a ratio 10:1) for 5 days followed by 3 -day expansion in IL-2. Naive T-cell primings with DCs were performed also in the presence of IL-4 or IL-12. Data are representative of at least three independent experiments. 
(CXCR6), is preferentially expressed in subsets of Th or Tc type 1 cells in blood. Since Bonzo is expressed by small subsets (2-6\% of CD4 and $4-12 \%$ of CD8 cells) of circulating $\mathrm{T}$ cells, Bonzo ${ }^{+} \mathrm{T}$ cells represent on average only $16 \%( \pm 5, n=5)$ of total blood Th1 cells and $26 \%( \pm 8, n=4)$ of Tc1 cells. Thus, Bonzo seems to mark functionally specialized $\mathrm{T}$ cells within the total Th1 or Tc1 cell pool. In contrast, it is displayed by very few (1-2\%) Th2 or Tc2 cells. The enrichment of activated $\mathrm{Bonzo}^{+} \mathrm{T}$ cells in rheumatoid and psoriatic arthritis synovial fluid and inflamed liver suggest possible roles of Bonzo in T-cell homing to chronically inflamed tissue sites. T cells in inflamed synovial fluids are very efficient producers of Th1 cytokines, when compared with blood counterparts (data not shown), and it is interesting in this regard that Bonzo ${ }^{+}$ $\mathrm{T}$ cells, highly polarized Th1 or Tc1 cells, are also enriched in these tissues. Whether CXCR6 is critical for localization of $\mathrm{T}$ cells in these effector sites or for targeting of cells to particular environments in these sites, or more likely, acts coordinately with other chemoattractant receptors in these processes (3), remains to be determined. Other receptors, such as CXCR3 and CCR5, are also expressed on these tissueeffector T cells $(25,26)$ and are likely to participate in homing to tissue-effector sites as well. It is also possible that $\mathrm{Bonzo}^{+} \mathrm{T}$ cells may be generated from Bonzo $\mathrm{T}$ cells after localization in the tissues.

Bonzo $^{+}$CD4 $\mathrm{T}$ cells in many ways display characteristics of memory Th cells with high effector function. These include such features as preferential expression of Bonzo on $\mathrm{CD}_{27}{ }^{-}$versus $\mathrm{CD} 27^{+}$memory CD $4 \mathrm{~T}$ cells and reduced expression of CCR7 and CD62L, characteristics seen on tissue-homing cells that efficiently produce effector T-cell cytokines. In this regard, half of the Bonzo ${ }^{+} \mathrm{CD} 4 \mathrm{~T}$ cells can produce IFN- $\gamma$, a level greatly enhanced from that of total CD4 T cells. Expression of CLA and/or of high levels of $\alpha 4 \beta 7$ on many Bonzo ${ }^{+}$ $\mathrm{T}$ cells also support their extralymphoid tissue homing potential. Furthermore, we positively correlated Bonzo expression with that of CD56 on T cells. CD56 ${ }^{+} \mathrm{T}$ cells are enriched for effector activities such as enhanced cytotoxic function in CD8 T cells (18). In this regard, most $\mathrm{Bonzo}^{+} \mathrm{CD} 8 \mathrm{~T}$ cells are armed with intracellular granzyme A and are efficient in IFN- $\gamma$ production.

The overall expression pattern of Bonzo on leukocytes in humans and mice is similar $(13,15)$. However, one notable difference is that Bonzo is expressed also by naive CD8 $\mathrm{T}$ cells in mice, while it is specifically expressed on memory/effector CD8 T cells in humans, as evidenced in this study. Based on CXCL16 expression on DCs in mice, Matloubian et al. speculated that Bonzo may be important for DC interaction with CD8 $\mathrm{T}$ cells. However, we feel this is unlikely because the Bonzo expression by naive CD8 T cells is extremely low and not functional (13), while that by activated/effector $\mathrm{T}$ cells is high and supports efficient chemotaxis. Thus, even in mice, functional Bonzo appears to be expressed by memory/effector, but not naive, $\mathrm{T}$ cells.
We also demonstrate in this study that DCs induce Bonzo expression on T cells destined to become polarized type 1 cells during primary activation of naive $\mathrm{T}$ cells. IL-12 is a potent cytokine that enhances Bonzo expression, while IL-4 inhibits it, suggesting Bonzo expression is tightly regulated by the balance between Th1/2 cytokines. In this regard, the expression of the Bonzo ligand by DC in lymphoid tissues suggests a possible feedback mechanism for amplification of Th1 tissue responses (13). In this model, Bonzo $^{+} \mathrm{T}$ cells (particularly $\mathrm{CCR}^{+}$cells, approximately $25 \%$ of Bonzo $^{+}$cells or Bonzo ${ }^{+}$cells newly generated from naive $\mathrm{T}$ cells) may migrate to $\mathrm{DC}$, producing enhanced type 1 cytokine conditions at the sites of additional $\mathrm{T}$ and APC interactions, thus increasing the generation of $\mathrm{BonzO}^{+} \mathrm{T}$ cells. CCR7Bonzo $^{+}$cells may gain access to DCs after draining through lymphatics into lymphoid tissues. Moreover, it is known that DCs are found not only in lymphoid tissues but also in nonlymphoid tissues such as synovium (27). Thus, CCR7- Bonzo $^{+}$cells can gain access to nonlymphoid tissues and interact with differentiated DCs. The regulation of the "Th1" chemokine receptor Bonzo by Th1 cytokines, in combination with the expression of the Bonzo ligand by DC, may thus permit a novel mechanism for the self-regenerating feedback control of Th1 versus Th2 inflammation, in which specific homing properties combine with associated cytokine production to enhance local Th1 cell inflammation - as seen, for example, in the dramatic enrichment of Bonzo ${ }^{+} \mathrm{T}$ cells in rheumatoid arthritis synovia, a typical type 1 autoimmune disease.

In conclusion, we propose that fundamental and functional specialization of $\mathrm{T}$ cells, as evidenced by generation of highly polarized type $1 \mathrm{Bonzo}^{+} \mathrm{T}$ cells by DCs, begins to occur early during the primary immune reaction against antigen in lymphoid tissues. Our data suggest that Bonzo may be important in trafficking of Th1 and Tc1 cells into effector tissue sites, and Bonzo ${ }^{+} \mathrm{T}$ cells with high effector function may be critical mediators of type 1 inflammation. The findings suggest that Bonzo should be investigated as a therapeutic target in diverse inflammatory diseases mediated by pathological activities of effector $\mathrm{T}$ cells. They also raise the possibility that Bonzo $^{+} \mathrm{T}$ cells, through a counter-regulatory role, may be useful for the treatment of type 2 diseases such as asthma and allergic disease.

\section{Acknowledgments}

We thank Dan Littman (New York University, New York, New York, USA) for other collaboration on Bonzo. This work was supported by grants from the NIH to E.C. Butcher, to H.B. Greenberg (V19 AI40034), and to J. Boisvert (5T32 AI-07328), and by awards from the Department of Veterans Affairs to E.C. Butcher and H.B. Greenberg. C.H. Kim is a Leukemia and Lymphoma Society fellow. E.J. Kunkel is a recipient of Arthritis Foundation postdoctoral fellowship. 
1. Butcher, E.C., Williams, M., Youngman, K., Rott, L., and Briskin, M. 1999. Lymphocyte trafficking and regional immunity. Adv. Immunol. 72:209-253.

2. Murphy, P.M., et al. 2000. International union of pharmacology. XXII. Nomenclature for chemokine receptors. Pharmacol. Rev. 52:145-176.

3. Foxman, E.F., Campbell, J.J., and Butcher, E.C. 1997. Multistep navigation and the combinatorial control of leukocyte chemotaxis. J. Cell. Biol. 139:1349-1360

4. Mantovani, A. 1999. The chemokine system: redundancy for robust outputs. Immunol. Today. 20:254-257.

5. Kim, C.H., Pelus, L.M., White, J.R., and Broxmeyer, H.E. 1998. Differential chemotactic behavior of developing $\mathrm{T}$ cells in response to thymic chemokines. Blood. 91:4434-4443.

6. Bowman, E.P., et al. 2000. Developmental switches in chemokine response profiles during B cell differentiation and maturation. J. Exp. Med. 191:1303-1318.

7. Campbell, J.J., Pan, J., and Butcher, E.C. 1999. Cutting edge: developmental switches in chemokine responses during T cell maturation. $J$. Immunol. 163:2353-2357.

8. Sallusto, F., Lenig, D., Mackay, C.R., and Lanzavecchia, A. 1998. Flexible programs of chemokine receptor expression on human polarized $\mathrm{T}$ helper 1 and 2 lymphocytes. J. Exp. Med. 187:875-883.

9. Bonecchi, R., et al. 1998. Differential expression of chemokine receptors and chemotactic responsiveness of type $1 \mathrm{~T}$ helper cells (Th1s) and Th2s. J. Exp. Med. 187:129-134.

10. Zingoni, A., et al. 1998. The chemokine receptor CCR8 is preferentially expressed in Th2 but not Th1 cells. J. Immunol. 161:547-551.

11. D'Ambrosio, D., et al. 1998. Selective up-regulation of chemokine receptors CCR4 and CCR8 upon activation of polarized human type $2 \mathrm{Th}$ cells. J. Immunol. 161:5111-5115.

12. Loetscher, P., et al. 1998. CCR5 is characteristic of Th 1 lymphocytes. Nature. 391:344-345.

13. Matloubian, M., David, A., Engel, S., Ryan, J.E., and Cyster, J.G. 2000. A transmembrane CXC chemokine is a ligand for HIV-coreceptor Bonzo. Nat. Immunol. 1:298-304.

14. Deng, H.K., Unutmaz, D., KewalRamani, V.N., and Littman, D.R. 1997. Expression cloning of new receptors used by simian and human immunodeficiency viruses. Nature. 388:296-300.

15. Unutmaz, D., et al. 2000. The primate lentiviral receptor
Bonzo/STRL33 is coordinately regulated with CCR5 and its expression pattern is conserved between human and mouse. J. Immunol. 165:3284-3292.

16. Van Lier, R.A., et al. 1988. Anti-CD27 monoclonal antibodies identify two functionally distinct subpopulations within the CD4+ T cell subset. Eur. J. Immunol. 18:811-816.

17. Hayes, M.P., Berrebi, G.A., and Henkart, P.A. 1989. Induction of target cell DNA release by the cytotoxic T lymphocyte granule protease granzyme A. J. Exp. Med. 170:933-946.

18. Pittet, M.J., Speiser, D.E., Valmori, D., Cerottini, J.C., and Romero, P. 2000. Cutting edge: cytolytic effector function in human circulating CD8+ $\mathrm{T}$ cells closely correlates with CD56 surface expression. $J$. Immunol. 164:1148-1152.

19. Kim, C.H., and Broxmeyer, H.E. 1999. Chemokines: signal lamps for trafficking of $\mathrm{T}$ and $\mathrm{B}$ cells for development and effector function. $J$. Leukoc. Biol. 65:6-15.

20. Sallusto, F., Lenig, D., Forster, R., Lipp, M., and Lanzavecchia, A. 1999. Two subsets of memory $\mathrm{T}$ lymphocytes with distinct homing potentials and effector functions. Nature. 401:708-712.

21. Annunziato, F., et al. 1999. Assessment of chemokine receptor expression by human Th1 and Th2 cells in vitro and in vivo. J. Lenkoc. Biol. 65:691-699.

22. Yamamoto, J., et al. 2000. Differential expression of the chemokine receptors by the Th1- and Th2-type effector populations within circulating CD4+ T cells. J. Leukoc. Biol. 68:568-574.

23. Nanki, T., and Lipsky, P.E. 2000. Lack of correlation between chemokine receptor and $\mathrm{T}(\mathrm{h}) 1 / \mathrm{T}(\mathrm{h}) 2$ cytokine expression by individual memory $\mathrm{T}$ cells. Int. Immunol. 12:1659-1667.

24. Andrew, D.P., et al. 2001. C-C chemokine receptor 4 expression defines a major subset of circulating nonintestinal memory $\mathrm{T}$ cells of both Th1 and Th2 potential. J. Immunol. 166:103-111.

25. Loetscher, P., et al. 1998. CCR5 is characteristic of Th1 lymphocytes. Nature. 391:344-345.

26. Qin, S., et al. 1998. The chemokine receptors CXCR3 and CCR5 mark subsets of T cells associated with certain inflammatory reactions. J. Clin. Invest. 101:746-754.

27. Thomas, R., Davis, L.S., and Lipsky, P.E. 1994. Rheumatoid synovium is enriched in mature antigen-presenting dendritic cells. J. Immunol. 152:2613-2623 